\title{
Inflation Expectations of the Inattentive General Public MONIQUE REID
}

May 2012

\section{Stellenbosch Economic Working Papers: 08/12}

KEYWORDS: SOUTH AFRICA, STICKY INFORMATION, INFLATION EXPECTATIONS, INATTENTIVE GENERAL PUBLIC

JEL: D82, D83, E31, E52, E58

MONIQUE REID DEPARTMENT OF ECONOMICS UNIVERSITY OF STELLENBOSCH

PRIVATE BAG X1, 7602

MATIELAND, SOUTH AFRICA

E-MAIL: MREID@SUN.AC.ZA 


\title{
Inflation Expectations of the Inattentive General Public
}

\author{
Monique Reid*
}

\begin{abstract}
The majority of academic research on central bank communication bas analysed a central bank's audience as a single group. Analyses, especially empirical research, have focused almost exclusively on a central bank's interaction with the financial markets, facilitated by the availability of high-quality, high-frequency asset price data. In practice, a central bank's audience is heterogeneous, and recognising this is advantageous for both modelling purposes and effective central bank communication. Many central banks use a range of communication tools to reach their various audiences, but little formal analysis has been conducted to guide policy design and communication strategies. Gathering and processing information are costly for the general public, so they make rational decisions that limit the time and resources they allocate to these tasks. As a result, aggregate inflation expectations of the public as a whole can be described as 'sticky' in that the spread of information about inflation expectations through the economy is not instantaneous. $A$ body of literature has emerged over the past decade, led by Mankin and Reis (2001), who developed the Sticky Information Phillips Curve (SIPC), and Carroll (2002, 2003), who proposed microfoundations for the SIPC. This paper follows Carroll (2002, 2003) in adopting epidemiological models to provide insight into how the general public in South Africa forms its inflation expectations. This enables an estimation of the speed at which the South African general public updates its inflation expectations (information stickiness). Agent-based models, which explain the complex aggregate inflation expectations of the general public from the agent level upwards, are then used to verify these estimates of information stickiness and explore the microfoundations of aggregate inflation expectations.
\end{abstract}

JEL Classification: D82, D83, E31, E52, E58

Keywords: South Africa, sticky information, inflation expectations, inattentive general public

\section{INTRODUCTION}

Central banks recognise that they are engaged in a strategic interaction with the citizens of their countries (their audiences) and that the inflation expectations of these citizens represent a channel through which monetary policy can achieve its policy objective of low and stable inflation.

\footnotetext{
* Department of Economics, Stellenbosch University. CGW Schumann building, Bosman Street, Stellenbosch, 7600, South Africa, Tel: +27 (0)21 808-4753,

The author acknowledges financial support for this project from Economic Research Southern Africa. This paper is also available as ERSA working paper number 279.
} 
Therefore, communication is widely recognised as crucial to the implementation of monetary policy, as it is used to build credibility, manage citizens' inflation expectations and improve coordination between the actions of the central bank and the citizens, which is mutually beneficial.

In analyses of South African monetary policy, the audience of the South African Reserve Bank (SARB) has almost always been treated as a single group, and empirical research has focused solely on the interaction of the SARB with the financial markets. Analysts do periodically acknowledge that the SARB's audience comprises a heterogeneous group of people, and the SARB has designed a range of communication tools in recognition of these differences. However, there has been little formal or comprehensive analysis of the characteristics of these different groups. This lack of attention devoted to understanding the non-financial market segments of the SARB's audience need not suggest that researchers believe these groups behave very similarly to the financial markets, or that the impact of these groups' behaviour is negligible and not worth studying. Instead, it reflects challenges such as the lack of relevant, high-frequency asset prices available to capture and model the views of the general public.

In practice, a central bank's audience comprises heterogeneous groups, and both the policy and communication of the central bank should be designed with this in mind. Although it is impractical to attempt to incorporate the full range of heterogeneity within a single economic model, it does seem beneficial to identify broad characteristics that are likely to affect the way the central bank's communication is received and interpreted, and to tailor communication to broad groups of the central bank's audience divided along these lines. Blinder and Wyplosz (2004) divide the central bank's audience into the broad public and its political representatives on one side, and the financial markets on the other. Cukierman (2005) argues that the general public will rationally choose to be inattentive to short-term fluctuations in the inflation rate if the central bank has credibility, as the cost to them of searching for and processing information about monetary policy outweighs the potential benefits. 
This paper studies the process by which the inattentive general public form their inflation expectations in South Africa. Firstly, a better understanding of the process by which the inattentive general public, who are responsible for the majority of the price setting behaviour in South Africa, form their expectations will improve the SARB's ability to communicate effectively with them and to influence their inflation expectations. Successful communication is essential both to enhance the effectiveness of monetary policy and to build public support for the institutional framework within which monetary policy is implemented.

Secondly, an improved understanding of the microfoundations of aggregate inflation expectations will enable better-quality modelling of the South African Phillips curve and advance policy analyses. For monetary policymakers, the benefits of improved modelling of the Phillips curve and insight into the microeconomic foundations of its dynamics are unquestionable. These would improve their ability to explain the time-varying effects of monetary policy on inflation and output, and thereby assist the implementation of monetary policy. The "inexorable and mysterious trade-off between inflation and unemployment" (Mankiw, 2001: 45) is fundamental to our understanding of monetary policy. It is impossible to explain the business cycle without it, and there is broad consensus that there is a trade-off between inflation and unemployment in the short run, but not in the long run, so any reasonable model of the economy should strive to capture these features.

\section{THE INATTENTIVE GENERAL PUBLIC}

Blinder, Ehrmann, Fratzscher, De Haan and Jansen (2008) review the literature on the contribution of central bank communication to the successful implementation of monetary policy and suggest some areas where further research is required. In the closing paragraph, they identify the need to research the role of the general public as a separate audience with whom a central bank is communicating.

"Finally, virtually all the research to date has focused on central bank communication with the financial markets. It may be time to pay some attention to communication with the 
general public. Admittedly, studying communication with the general public will pose new challenges to researchers - not least because the financial market prices will be less relevant. But the issues are at least as important. In the end, it is the general public that gives the central bank its legitimacy, and hence their independence."

(Blinder et al., 2008: 47)

Blinder et al. (2008) stress the importance of studying the communication of the central bank with the general public, despite the difficulty of doing so. The inflation expectations of this group have a substantial effect on the ability of monetary policymakers to achieve low and stable inflation. Literature from the field of behavioural economics is used in this section to improve our understanding of the incentives facing the inattentive general public and their behaviour under these conditions. Next, we begin to explore the implications for modelling inflation expectations.

\subsection{RATIONAL INATTENTION}

Proponents of behavioural economics have long contested the use of the standard utility maximising agent model adopted by mainstream economics. They argue that the amount and quality of information that rational economic man is assumed to possess, and the clear and stable set of preferences used to describe his utility are unrealistic. In addition, they question the ability of rational economic man to evaluate the range of options available to him and calculate which will enable him to optimise his utility, given his preferences and budget constraint (Simon, 1955, 1956). In essence, behavioural economists criticise mainstream economists for ignoring the limits to economic man's knowledge and computational ability.

Proponents of the standard model respond by arguing that the assumption of rationality does not suggest that people are fully able to perform optimisation calculations for every decision they make. People do not know the future with certainty. Rather, they propose that people's expectations and behaviour will be guided by their best guesses, based on all the information they have available to them. They will also avoid systematic errors, which are predictable and costly (Klamer, 1984). Rational 
expectations can be viewed as an analytical condition that excludes these systematic errors, rather than an assumption that economic man has perfect knowledge and computational ability. However, the debate surrounding the validity of rational expectations and its implications has not been settled yet.

The reality is that monetary economists require a pragmatic approach to making policy recommendations while the theoretical debate continues. Monetary policy makers need to make important policy decisions now, despite the lack of consensus. Whatever one's ideological view, it is difficult to deny that sensible monetary policy must account for the formation of expectations, ${ }^{1}$ and it is, by definition, not possible to model 'irrational expectations'. Rational expectations models do not fully explain the complexity of individual decisions, but the assumption does provide a way to incorporate expectations into the model when decisions are made in a dynamic setting. A compromise such as using the standard rational models, modified or extended to account for the limitations of human ability that behavioural economics has highlighted, seems like a reasonable way to address the pressing questions asked by applied macroeconomic research.

It is argued here that an examination of Simon's concept of bounded rationality shows that this compromise does not require a substantial concession on the part of the behavioural economists. Among the critics of the standard view, Herbert Simon takes a prominent place. He did not try to replace 'rational' economic man with an 'irrational' economic man. His aim was instead to redefine economic man as an agent that is still essentially rational, but who is limited in some way, such as having limited information or computational ability (Simon, 1955, 1956).

Behavioural economists have offered numerous examples of deviations from the standard model, which Della Vigna (2007) divides into three broad groups: non-standard preferences, non-standard

\footnotetext{
${ }^{1}$ There is broad consensus that monetary policy affects the economy with long and variable lags, so monetary policy
} must be forward-looking. 
beliefs, and non-standard decision-making. The concept of rational inattention falls into the third group - non-standard decision-making. Rationally inattentive agents recognise that gathering and processing information is costly, so they make rational decisions to limit the amount of time and money they allocate to the task (Della Vigna, 2007; Birchler and Bütler, 2007).

Monetary models are continually being extended to improve their explanation of monetary policy's impact on the economy. These extensions have especially tried to grapple with uncertainty and learning. A great deal of research is going into explaining deviations from instantaneous market clearing and the assumption of perfect rationality. The Keynesian explanation for temporary deviations from market clearing, used extensively to estimate New Keynesian Phillips Curves (NKPCs), is that prices are sticky as it is costly to adjust them (Calvo, 1983). Other leading explanations include Lucas's (1972) signal extraction problem and the learning literature (Sargent, 1993; Evans and Honkapohja, 2001; and others).

In this paper, the behavioural economics concept of rational inattention is used to modify the standard models, with the objective of modelling the actual data more accurately. The aim of adopting a different model is to improve our description of the process by which inflation expectations are formed, in order to overcome some of the troubling weaknesses of current macroeconomics models, which will be explored further on.

At this point, it is important to distinguish the connotations of the term 'rational inattention' as used by the behavioural economists from that used in the monetary literature. In the behavioural economics literature, rational inattention refers to a deviation from the standard rational expectations model, and it acknowledges that due to the costs involved in accessing and processing information, it is rational for economic agents to limit the time and resources devoted to the task.

In the monetary literature, two new forms of incomplete information have been developed to introduce rigidity into the monetary models. Christopher Sims $(2005,2007)$ has adopted ideas from 
engineering communications theory to model his suggestion that people have limited capacity to process and transmit information. In his models, economic agents have partial information (they receive noisy information), and he calls this 'rational inattention'. Although Sims' rational inattention is intuitively appealing, the technical challenge of incorporating it into macroeconomic and financial models is substantial. Sims himself describes its progress as 'modest' (Sims, 2010: 38), although he remains positive about its future potential.

In contrast, Reis (2004) adopted the term 'inattentiveness' to describe his modelling of economic agents who have delayed information because they have many competing needs that they devote their time and resources to, and who optimally choose to update their information only sporadically. This form of incomplete information was used by Mankiw and Reis (2001a, 2001b, 2006, 2007) in their 'sticky information Phillips curve' (SIPC) models, which were developed as an alternative to sticky price models. Far more progress has been made in incorporating 'inattentiveness' into macroeconomic models than Sims's 'rational inattention'. Mankiw and Reis (2006) had already offered a DSGE model in 2006, in which information about prices, wages and consumption are all sticky (pervasive stickiness) rather than only price information. Following the earlier argument that policy decisions cannot wait for perfect theory or models, and given the applied nature of this study, Mankiw and Reis's 'inattentiveness' will be adopted in this paper. The aim is to provide microfoundations for the estimation of the South African SIPC.

Mankiw and Reis (2001a, 2001b) claim that sticky information is more consistent than rational expectations with mainstream views about the actual dynamics of the macroeconomic variables inflation and unemployment. The idea of inattentiveness also has intuitive appeal in the South African context. Ehlers and Steinbauch (2010) investigated the expectation formation processes of different economic groups in South Africa. They found that the groups neither employed fully rational nor fully adaptive behaviour. Rather, the different groups appeared to adopt different combinations of rational and adaptive behaviour, which Ehlers and Steinbauch (2010: abstract) describe as 'non-homogenous learning'. This paper focuses on using inattentiveness as an alternative 
explanation for the non-homogenous formation of inflation expectations by different groups in the South African economy, in an attempt to address the concerns raised by Mankiw (as discussed in section 3).

\section{MODELLING THE INFLATION EXPECATIONS OF THE INATTENTIVE GENERAL PUBLIC}

Mankiw (2001: 52) laments that the NKPC "cannot come even close to explaining the dynamic effects of monetary policy on inflation and output". He identifies three empirical findings that he believes highlight its failure. The NKPC predicts that when monetary policy is fully credible, a disinflation can cause an economic boom, which is at odds with experience; and it does not generate the inflation persistence that we observe in reality. But Mankiw argues that it is the implausible impulse response functions that illustrate the weakness of the NKPC most clearly. They are not able to simultaneously capture two things on which there is wide consensus within monetary economics - that monetary policy has a temporary effect on employment and a delayed and gradual effect on inflation. Mankiw and Reis's (2002) proposal to model economic agents as 'inattentive' stems from their frustration with the inability of the NKPC to adequately represent the monetary transmission mechanism.

Although a substantial amount of research has been dedicated to modelling a Phillips Curve that explains the observed data well, most of this effort has been focused on modifying or extending the NKPC. Mankiw (2001) argues that these modifications do not solve the underlying deficiencies of the model in a satisfactory manner. For example, to introduce inflation persistence, Fuhrer and Moore (1995) added some backward-looking expectations, which are not grounded in solid theoretical foundations.

Instead, Mankiw and Reis (2001) proposed that the Phillips curve be modelled using sticky information rather than sticky prices. They proposed that sticky information was the result of the fact that the general public are inattentive to short-term changes in inflation and that they only 
update their inflation expectations periodically. However, they did not formalise their proposed microfoundations.

Research by Roberts (1997) did focus some attention on the microeconomic reasons for the failure of the NKPC to explain observations of the economy. He argues that there are two deviations from the standard New Keynesian model, either of which provides a way to address the problematic 'disinflationary boom' prediction. Roberts refers to past studies (Phelps, 1978; Taylor, 1983; Ball' 1991; Fuhrer and Moore, 1992, 1995) which show that a sticky price model does not guarantee sticky inflation. As discussed earlier, it is possible in a New Keynsian model for an increase in inflation to have no impact on output, if the central bank is credible. Fuhrer and Moore (1995) showed that the assumption of sticky inflation was able to explain the observed data better than that of sticky prices (conditional on rational expectations). However, Roberts (1997) argues that similar results can be achieved by assuming sticky prices and imperfectly rational expectations. He evaluates these two hypotheses and concludes that it is preferable to adjust the assumption of rational exceptions (1997), because survey evidence shows that inflation is not sticky and supports the hypothesis that inflation expectations are less than perfectly rational.

Building on this survey-based evidence of Roberts that expectations are less than rational (1997, 1998) and the claims of Mankiw and Reis (2001a, 2001b) that the sticky information models better explain some of the macroeconomic dynamics, Christopher Carroll $(2002,2003)$ proposed a way to represent the microfoundations of the aggregate behaviour that the SIPC models are producing. $\mathrm{He}$ adopted epidemiological models, particularly for their approach to studying the spread of contagious diseases, to represent the dissemination of information about inflation throughout a population of economic agents.

According to Carroll (2002, 2003), of the entire audience with which the central bank communicates, only the professional forecasters (which constitute a small fraction of the public) form their own expectations. The rest of the public form their expectations based on the media's explanation of the 
professional forecasts. In effect, Carroll proposes that the manner in which the inattentive general public collect information about monetary policy can be modelled in the same probabilistic manner as people in a population contract a contagious disease. An epidemiological model is employed in this paper to capture the actual behaviour of the inflation expectations of the inattentive general public in South Africa.

\subsection{THEORETICAL MODEL}

In line with Carroll (2002, 2003), a 'common source' epidemiological model was adopted, which relies on the following assumptions. A person has a fixed probability of contracting a disease if exposed to it for a given period, and once infected, he or she never recovers. In addition, the 'common source' assumption implies that the disease is caught from a common source (such as a central air conditioner in a building), so the people in contact with this source have a constant probability of catching the disease. Carroll assumes that the inattentive public update their inflation and unemployment expectations periodically based on exposure to newspapers which report the expectations of the professional forecasters. The common source of information is the professional forecast reported in the newspapers, and information is transmitted though the economy in a sluggish fashion, based on the probability that people adjust their inflation expectations to align with the professional forecasts.

We assume that in each period $t$, each member of the general public (called a price setter in the model $\left.^{2}\right) i$, has a probability $\lambda$, of being exposed to the relatively more rational inflation expectations of the financial analysts ${ }^{3}$, via a media report. Conversely, each price setter faces a probability (1-ג) of not being exposed to this information and therefore retaining his or her inflation expectations from

\footnotetext{
${ }^{2}$ In the model, members of the general public are referred to as the price setters, to reflect that this group consists of the majority of the public (it excludes only the financial market), including the business sector that sets the prices of goods and services, and labour that influences the price of wages.

${ }^{3}$ Ehlers and Steinbauch (2010) found that the inflation expectations of the financial analysts are more rational than those of the business sector or the trade unions.
} 
period (t-1). The mean inflation expectations of the price setters as a group in time $\mathrm{t}$ are determined by the mean inflation expectations of the financial analysts in time $t$ and the weighted average of past inflation expectations of the price setters, as follows:

$$
\pi_{\mathrm{t}}^{\mathrm{e} \text {.PS }}=\lambda \pi_{\mathrm{t}}^{\mathrm{e} . \mathrm{FA}}+(1-\lambda)\left\{\lambda \pi_{\mathrm{t}-1}^{\text {e.PS }}+(1-\lambda)\left(\lambda \pi_{\mathrm{t}-2}^{\text {e.PS }}+\ldots\right)\right\}
$$

$\pi_{\mathrm{t}}^{\text {e.PS }}$ and $\pi_{\mathrm{t}}^{\text {e.FA }}$ represent the mean inflation expectations of price setters and of financial market participants respectively, for the following year, beginning at time t. Intuitively, equation 1 states that the current mean of the expected inflation of price setters for the following year is equal to the mean current newspaper forecast for that period and the weighted average forecasts of the price setters for the same period, as forecast in previous periods. The probability that price setters in time $t$ will update their inflation expectations to that of the financial analysts for the same period is captured by coefficient $\lambda$. In this simple model, all price setters who update their inflation expectations to those of the financial analysts keep them constant at the level they expected at the start of the period, so there is a probability $(1-\lambda)$ that price setters maintain their expectations from the previous period.

This model could be extended to capture other sources of inflation information, such as media reports of past inflation figures or social interaction between price setters. The empirical results presented further on in this paper support the view that past inflation does play a significant role in the formation of inflation expectations of the general public in South Africa (OECD, 2010). When past inflation is added to equation 1 , there is a probability, $\lambda$, that the price setters will align (update) their inflation expectations to those of the financial analysts. If not, there is a probability, $\delta$, that they will be exposed to information about past inflation and will align their inflation expectations to this figure and a probability, (1- $\delta)$, that that they will retain their inflation expectations from period $\mathrm{t}-1$. 
Given this description of the process by which price setters update their inflation expectations with information from the financial analysts (via newspapers) and past inflation figures, it is possible to estimate the speed at which they update their expectations. Rearranging the equations into the error correction form is a natural way to isolate information stickiness from the speed of adjustment coefficient, which is employed for the empirical estimation in section 6.

\section{THE DATA}

\subsection{THE DATA}

The dataset comprises four series: inflation, past inflation, the inflation expectations of financial analysts and the inflation expectations of price setters. The data is at a quarterly frequency and the small sample size of 40 observations (2000Q3 - 2010Q2) is limited by the availability of inflation expectations data. The Bureau for Economic Research (BER) began conducting inflation expectations surveys for the SARB from September 2000, with the objective of providing information for the implementation of inflation targeting, and there is no comparable inflation expectations data for the general public obtained before this survey.

Following an announcement by the Minister of Finance in October 2008, the SARB began, in January 2009, to use the CPI rather than the CPIX as its official proxy for inflation ${ }^{4}$. Between 2005 and 2008 steps had been taken to improve the CPI basket, and by 2009 it was deemed to be the most comprehensive measure of the cost of living in South Africa and a more appropriate official proxy of inflation (Statistics South Africa, 2009a; Statistics South Africa, 2009b). The changes made to the CPI included routine adjustments to reflect changes with respect to expenditure patterns, technology and tastes, but they also reflected a change in the way in which the costs of accommodation were recorded. In its previous form, the CPI included interest rates on mortgage

\footnotetext{
${ }^{4}$ Various measures of the cost of living are calculated each month (for example CPI, CPIX and PPI). These are used as proxies for inflation, but the SARB recognises that inflation is not perfectly captured by any one price index and considers a number of them when making policy decisions (Mohr, 2008).
} 
bonds, whereas in its new form, it adopts 'owners' equivalent rent', which accounts for the rent foregone when a person lives in the house he or she owns. In this study, the focus is on inflation itself, and the series used as a proxy consists of the CPIX up to the end of 2008 and the CPI thereafter, which can be viewed as the 'targeted price index'.

As a consequence of this change, the BER surveyed the expectations of the CPIX up to the end of 2008 and the CPI thereafter. However, it is argued here that both actual inflation and the inflation expectations series can be treated as continuous variables (expectations of the targeted price index), and this need not be treated as a structural break. This proposition was tested by visual inspection of the series (Figure 1), stability tests (CUSUM and CUSUMSQ tests) conducted on the models used later in the paper, as well as by comparisons of the results of regressions that include only the sample up to the change of target variable ${ }^{5}$. This assumption does not appear to bias the results of this study.

The model variables are constructed so that each has a constant horizon of one year. Using a combination of the South African Reserve Bank Quarterly Bulletins and the Statistics South Africa CPI series, a real-time ${ }^{6}$ inflation series with a horizon of one year was constructed. Each observation of the inflation series represents targeted inflation from time $t$ to $t+4$. Similarly, the past inflation series is a series of real-time observations of past inflation from periods $\mathrm{t}-1$ to $\mathrm{t}-5$.

The inflation expectations series had to be manipulated to have a constant horizon of 1 year. The BER administers the inflation expectations surveys of three economic groups - financial analysts, business representatives and trade unions. Each quarter, members of each of these groups are asked to predict what they expect annual inflation to be in the current year, the following year, and the year after that. Therefore, the horizons of the predictions change from quarter to quarter, and the

\footnotetext{
5 These results are available in Table XI in the Appendix.

${ }^{6}$ To provide a more accurate representation of the economic decisions at the time, the data actually available in each period was collected. Final series for inflation, for example, those available on the SARB's website, have often been revised as more information became available. To ensure that the real-time data was considered, the series were constructed by referring to the original CPI and CPIX data releases by STATSA, rather than to a final series.
} 
inflation expectations with a 1 -year horizon had to be constructed from the original survey data ${ }^{7}$. These constant, 1-year horizon series are illustrated in Figure 1.

Figure 1

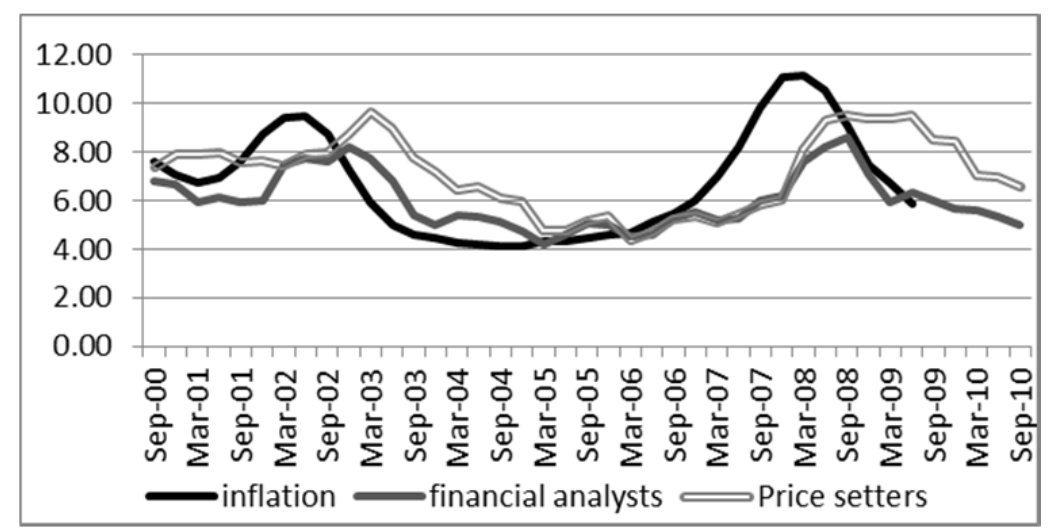

\subsection{STATIONARITY OF THE SERIES}

Before conducting any regression analyses the stationarity of the data series was investigated. Unfortunately, the small sample size available made it difficult to reach conclusions about the stationarity of the series. The augmented Dickey Fuller (ADF) and Phillips Perron (PP) tests were used first, but the results were mixed (Table Ia). The ADF test is known to have low power, and the PP does not perform well in small samples (Davidson and MacKinnon, 2004). Therefore Dickey Fuller Generalised Least Squares (DF GLS) and Ng-Perron tests were selected as they perform relatively better in small samples. These tests delivered robust results, suggesting that all the data series are stationary (Table $\mathrm{Ib})$.

${ }^{7}$ Crucially, in Q1 respondents are asked to forecast a larger proportion of the current year than in Q3 - the horizons of the forecasts change over the year. In order to construct a series with a constant one-year horizon, each quarter, a fraction of the current year is added to a fraction of the following year, depending on the quarter in which the survey is being conducted. For example, the one-year forecast in Q3 (for which the field work is conducted in August) consists of $25 \%$ of the current year's forecast and $75 \%$ of the following year's forecast. 
Table Ia: Augmented Dickey Fuller and Phillips Perron tests for data stationarity

\begin{tabular}{|c|c|c|c|c|c|}
\hline \multirow{2}{*}{ Variables } & \multicolumn{2}{|c|}{ ADF } & \multicolumn{2}{c|}{ PP } \\
\cline { 2 - 6 } & Levels & $\begin{array}{c}\text { First } \\
\text { difference }\end{array}$ & Levels & $\begin{array}{c}\text { First } \\
\text { difference }\end{array}$ & $\begin{array}{c}\text { Second } \\
\text { difference }\end{array}$ \\
\hline$\pi_{t}^{\text {e.FA }}$ & -2.531 & $-4.278^{* * *}$ & -1.758 & $-4.103 * * *$ & \\
\hline$\pi_{t}^{e . P S}$ & -1.883 & $-3.930 * * *$ & -1.637 & $-3.930 * * *$ & \\
\hline$\pi_{t}$ & $-3.133 * *$ & & -1.830 & $-3.771 * * *$ & \\
\hline$\pi_{\mathrm{t}-1}$ & $-3.577 * * *$ & & -1.744 & -2.197 & $-3.795 * * *$ \\
\hline
\end{tabular}

Note: Intercept, no trend. ***, ** and * indicate that the statistics are significant at the 1\%, 5\% and $10 \%$ levels. The first column for each test shows the results of the test in levels. When this first statistic is insignificant, the result of the test in first differences is shown in the second column, and in second differences in the third column.

Table Ib: Dickey Fuller GLS and Ng-Perron tests for data stationarity

\begin{tabular}{|c|c|c|c|c|c|}
\hline \multirow{2}{*}{} & \multirow{2}{*}{ DF-GLS } & \multicolumn{4}{|c|}{ Ng-Perron } \\
\cline { 3 - 6 } & & MZa & MZt & MSB & MPT \\
\hline Inflation & $-2.444^{* *}$ & Reject & Reject & Reject & Reject \\
\hline FA & $-1.884^{*}$ & Reject & Reject & Reject & Reject \\
\hline PS & $-2.796 * * *$ & Reject(5-10\%) & Reject(5-10\%) & Reject(5-10\%) & Reject(5-10\%) \\
\hline Past infl & $-2.668 * * *$ & Reject & Reject & Reject & Reject \\
\hline
\end{tabular}

Note: Intercept, no trend. ***, ** and * indicate that the statistics are significant at the 1\%, 5\% and 10\% levels. The first column for each test shows the results of the test in levels. When this first statistic is insignificant, the result of the test in first differences is shown in the second column.

These stationarity test results should be considered in the context of a long debate in the literature about whether inflation is stationary. Juselius (2006) warns against treating stationarity as a property of a variable, but as a sample property instead. She suggests modelling inflation as an I(1) variable to allow the persistent and less persistent components of the variables to be identified by the technique. These conflicting results for the unit root tests are taken into account when selecting the modelling techniques in for the formal analysis that follows in sections 5 and 6.

\section{THE DISSEMINATION OF INFLATION INFORMATION}

Before attempting to estimate information stickiness, it is sensible to establish whether inflation information disseminates from the economy to the financial analysts to the price setters as hypothesised. This is necessary to justify the adoption of epidemiological models to represent the spread of inflation information. Visual inspection of the inflation and inflation expectations series in 
Figure 1 shows that adjustments in the inflation series are followed by similar but lagged adjustments to the inflation expectations of the financial analysts, followed by those of the price setters.

A simple contemporaneous pairwise correlation matrix also offers insight into the degree to which these different data series 'share information'. Two features stand out. Firstly, the results in the top row of Table II reveal that the contemporaneous inflation expectations of financial analysts correlate with actual inflation to a much greater extent (0.684) than the inflation expectations of price setters do (0.400). Secondly, the contemporaneous correlation between the inflation expectations of financial analysts and price setters is strong (0.774).

Table II: Contemporaneous pairwise correlation matrix

\begin{tabular}{|l|c|c|c|}
\hline & Inflation & Price Setters & Financial Analysts \\
\hline Inflation & 1.000 & 0.400 & 0.684 \\
\hline Price Setters & 0.400 & 1.000 & 0.774 \\
\hline Financial Analysts & 0.684 & 0.774 & 1.000 \\
\hline
\end{tabular}

Granger causality tests (Table III) were used to investigate whether adjustments in one of the variables was informative about the likely future movements in the other variable. Although Granger causality does not prove that movements in the first variable induced particular movements in the second, it does show that they happened prior to and helped to forecast changes in the second. The hypothesis that the inflation expectations of price setters do not Granger cause the inflation expectations of financial analysts cannot be rejected for either 2 or 3 lags, and it is marginal for 1 lag. In contrast, the hypothesis that the inflation expectations of financial analysts do not Granger cause the inflation expectations of price setters is rejected at the $5 \%$ level of significance for lag lengths 1 to 3 .

Table III: Granger causality tests

\begin{tabular}{|l|l|l|l|}
\hline Hypothesis & $\begin{array}{l}\text { Probability } \\
(1 \text { lag })\end{array}$ & $\begin{array}{l}\text { Probability } \\
(2 \text { lags })\end{array}$ & $\begin{array}{l}\text { Probability } \\
(3 \text { lags })\end{array}$ \\
\hline$\pi_{t}^{e . P S}$ does not Granger cause $\pi_{t}^{\text {e.FA }}$ & 0.088 & 0.724 & 0.584 \\
\hline$\pi_{t}^{\text {e.FA }}$ does not Granger cause $\pi_{t}^{\text {e.PS }}$ & 0.000 & 0.011 & 0.025 \\
\hline
\end{tabular}


Therefore, exploratory data analysis provides preliminary evidence that there is 'shared information' between the three series and that changes in inflation tend to occur first, followed by similar adjustments in the inflation expectations of the financial analysts, followed by those of the price setters; hence, changes in the inflation expectations of financial analysts do help to predict changes in those of the price setters.

Finally, an examination of the forecasting accuracy of the two inflation expectations series can provide insight into which group is better able to use successfully the information they have at their disposal. The aim is not to test the rationality of the inflation expectations series, but rather to determine which is relatively more rational.

One way of evaluating the precision of the forecasts is by minimising the root mean squared error (RMSE) (Pindyck and Rubinfeld, 1998). This criterion compares the forecasted series with the actual series and allows the researcher to compare the ability of the two inflation expectations series to predict inflation. The RMSE is lower for the inflation expectations of the financial analysts than for the price setters, suggesting that financial analysts forecast with greater precision (Table IV).

Table IV: RMSE

\begin{tabular}{|l|l|}
\hline & RMSE \\
\hline $\boldsymbol{\pi}_{\boldsymbol{t}}^{\boldsymbol{e} . \boldsymbol{F A} \boldsymbol{A}}$ & 1.70 \\
\hline $\boldsymbol{\pi}_{\boldsymbol{t}}^{\boldsymbol{e} P \boldsymbol{S}}$ & 2.16 \\
\hline
\end{tabular}

In conclusion, financial analysts not only adjust their inflation expectations quicker, but more accurately than price setters. None of the exploratory data analyses discredit the proposed hypothesis about the spread of inflation information through the economy. 


\section{INFORMATION STICKINESS}

In this section, South African survey data is applied to an epidemiological model, to estimate how quickly South African price setters update their inflation expectations. This provides an estimate of information stickiness.

A correlation matrix (Table $\mathrm{V}$ ) is again adopted to examine the extent to which the inflation expectations of financial analysts, the inflation expectations of price setters and past inflation share information. We established in the previous section that there is a strong correlation between the inflation expectations of the financial analysts and the price setters, so what is interesting in this matrix is the exploration of the relationship between past inflation (average realised inflation over the past year) and each inflation expectations series (inflation expectations for the following year). This provides a first indication of the extent to which the inflation expectations of the group is backward-looking versus the degree to which the group looks to other (unspecified) sources of information to form its views.

Table V: Pairwise correlation matrix

\begin{tabular}{|l|c|c|c|}
\hline & Financial Analysts & Price Setters & Past Inflation \\
\hline Financial Analysts & 1.000 & 0.772 & 0.585 \\
\hline Price Setters & 0.772 & 1.000 & 0.927 \\
\hline Past Inflation & 0.585 & 0.927 & 1.000 \\
\hline
\end{tabular}

The correlation between past inflation and the financial analysts is 0.585 and that between past inflation and the price setters is 0.927 , which indicates that price setters rely to a much greater extent on past inflation than financial analysts do. By deduction, financial analysts use sources of information other than past inflation to a greater extent in the formation of their expectations. These correlations also suggest that it is important to include past inflation in a regression that attempts to explain the inflation expectations of the price setters, as will be done in the following section. 


\subsection{REGRESSION ANALYSIS}

Carrol $(2002,2003)$ estimated information stickiness for the US as approximately 0.27 , using single equation models of the form implied by the epidemiological models he had proposed. This allowed him to test restrictions using Wald tests such as $\pi_{\mathrm{t}}^{\mathrm{e} \text {.FA }}+\pi_{\mathrm{t}-1}^{\mathrm{e} \text {. PS }}=1$, in order to examine the ability of the model to explain the actual data. His results were supportive of the model. Table VI, below, offers a brief summary of Carroll's $(2002,2003)$ results, based on the following equation:

$$
\pi_{t}^{\text {e.PS }}=\beta_{0}+\beta_{1} \pi_{t}^{\text {e.FA }}+\beta_{2} \pi_{t-1}^{e . P S}+\beta_{3} \pi_{t-1}+\varepsilon_{t}
$$

Table VI: Carroll's (2001) estimation of information stickiness for the US

\begin{tabular}{|c|c|c|c|c|c|c|c|c|}
\hline \multirow[t]{2}{*}{ Equation } & \multirow[t]{2}{*}{$\beta_{0}$} & \multirow[t]{2}{*}{$\beta_{1}$} & \multirow[t]{2}{*}{$\beta_{2}$} & \multirow[t]{2}{*}{$\beta_{3}$} & \multirow[t]{2}{*}{$\overline{R^{2}}$} & \multirow{2}{*}{$\begin{array}{l}\text { Durbin } \\
\text { Watson }\end{array}$} & \multirow[t]{2}{*}{ Std Err } & Test \\
\hline & & & & & & & & $\mathrm{p}$-value \\
\hline 1 & & $0.36^{* * *}$ & $0.66^{* * *}$ & & 0.76 & 1.97 & 0.43 & $\begin{array}{c}\beta_{1}+\beta_{2}=1 \\
0.178\end{array}$ \\
\hline 2 & & $0.27^{* * *}$ & $0.73^{* * *}$ & & 0.76 & 2.12 & 0.43 & $\begin{array}{c}\beta_{1}=0.25 \\
0.724\end{array}$ \\
\hline 3 & $1.26 * * *$ & $0.50 * * *$ & $0.25^{* *}$ & 0.01 & 0.84 & 1.72 & 0.35 & $\begin{array}{l}\beta_{3}=0 \\
0.814\end{array}$ \\
\hline
\end{tabular}

NOTE: The results in this table correspond to equation 2 in the text above. Columns 1-4 report the coefficient values for different versions of the equation, and *** and ** indicate that these coefficients are significant at the 1\% and 5\% levels. Columns $5-7$ report some diagnostics for each model, and column 8 the results of $W$ ald tests (with the relevant $p$-values in brackets).

Starting with model 1 (row 1 of Table VI), Carroll estimated the proportion of the inflation expectations of price setters in period $t$ that could be explained by the inflation expectations of the financial analysts in period $t$, and the proportion explained by their own inflation expectations in the previous period. The sum of coefficients $\beta_{1}$ and $\beta_{2}$ is close to 1 , and the Wald test conducted to test this formally (reported in the final column) cannot be rejected. Given these promising results, Carroll restricted the sum of the 2 coefficients to 1 and re-estimated the equation, which yielded an estimate of 0.27 for information stickiness. He also tested whether the inclusion of a constant and past inflation improved the fit of the model and found that only the constant had important explanatory power. He interpreted this as a sign that social interaction between price setters was important in the formation of their inflation expectations, while past inflation was not. 
However, Carroll did not report any tests of weak exogeneity or comprehensive model diagnostics to support the appropriateness of his choice to use a single-equation model. In addition, the speed of adjustment (information stickiness) is easy to interpret when there are only two regressors (the inflation expectations of financial analysts and those of the price setters), but when the model is extended to include past inflation, for example, the speed of adjustment is better estimated directly using a model in the error-correction form. Models of the kind used by Carroll were estimated for South Africa and are available in Table VII in the Appendix, but there was concern that the model variables were nonstationary, which would have undermined the results.

Peraran et al. (1999) suggested that the error-correction form of the ARDL model offers a number of advantages when modelling series that are potentially nonstationary. The ARDL method avoids uncertainty surrounding the order of integration of data series, as the variables included in the model can be I(0), I(1), or cointegrated (Pesaran et al., 1999), and the method allows long-run and shortrun components of the data to be estimated simultaneously. Peraran et al. (1999) developed the bounds test as a means to test for cointegration within the ARDL model, and Narayan (2004) went on to use Pesaran et al.'s (1999) programming code to estimate critical F-statistics for sample sizes between 30 and 80 observations, improving the accuracy of the results when using small samples.

A weakness of the ARDL method is that it assumes by construction that only one variable is not weakly exogenous. Therefore, it is vulnerable to the incredible restrictions of which Sims (1980) warned. In this regard, the VECM approach is favourable, although relies on pretesting. There remains uncertainty about whether the regression variables are $\mathrm{I}(1)$ or $\mathrm{I}(0)$, but it is likely that they are integrated of the same order, given the very similar patterns of the series (Figure 1), which enable the use of the VECM. In addition, Juselius (2006) recommended treating inflation as an I(1) variable, despite the debate in the literature.

Given the uncertainty about the stationarity of the model variables and whether each is weakly exogenous, both the VECM and the ARDL models were used and their results compared in order 
to help identify any lack of robustness. Firstly, the interaction between the inflation expectations of price setters and financial analysts was modelled using a VECM (model 5 in column 2 of Table VIII). The Johansen cointegration technique indicated that there is one cointegrating relationship, and LR tests concluded that $\pi_{\mathrm{t}}^{\text {e.FA }}$ is weakly exogenous (row 2). Therefore, only $\pi_{\mathrm{t}}^{\text {e.PS }}$ responded to disequilibrium between the two variables in the previous period. The results of the cointegrating equation (the long-run relationship) for model 5 (reported in the 4th row) are questionable. This may be the consequence of the fact that the VECM suffers from omitted variable bias through the omission of past inflation, which according to the exploratory data analysis, plays such a substantial role in explaining the inflation expectations of price setters.

Model 5 was then re-estimated in the ARDL-ECM form (column 2 of Table X). Given the result from the VECM that $\pi_{\mathrm{t}}^{\mathrm{e} . \mathrm{FA}}$ is weakly exogeneous in this model, the ARDL form is well justified in this case. In order to estimate the ARDL in its error correction form, which is necessary to isolate the speed of adjustment parameter, the long-run equation was estimated first (row 2). The coefficient on $\pi_{\mathrm{t}}^{\mathrm{e} \text {. FA }}$ is far more reasonable than the coefficient in the cointegrating equation of the VECM, despite the fact that past inflation is still not included in the model. The full ECM-ARDL was then employed, where the speed of adjustment coefficient, representing information stickiness, was estimated to be 0.311 . This estimate differs quite substantially from that of the VECM, which raises concern about its robustness.

The second model used to estimate information stickiness was model 6, which is an extension of model 5 in that past inflation was included, prompted by the findings of the exploratory data analysis. A single cointegrating relationship was again identified by the Johanssen technique, but this time both $\pi_{\mathrm{t}}^{\mathrm{e} \text {.PS }}$ and $\pi_{\mathrm{t}}^{\mathrm{e} \text {. FA }}$ were classified as weakly exogenous, leaving past inflation as the dependent variable. This is not sensible because past inflation is predetermined, but in order to check that it was not, the forward-looking nature of inflation that was causing the result, past inflation was lagged progressively further into the past, and the relationship was retested. It was only after a lag of 6 or 7 quarters that $\pi_{\mathrm{t}}^{\mathrm{e} \text {.PA }}$ and $\pi_{\mathrm{t}}^{\text {e.PS }}$ started to react to changes in past inflation, which is not reasonable. 
Table VIII: Weak exogeneity and VECM results

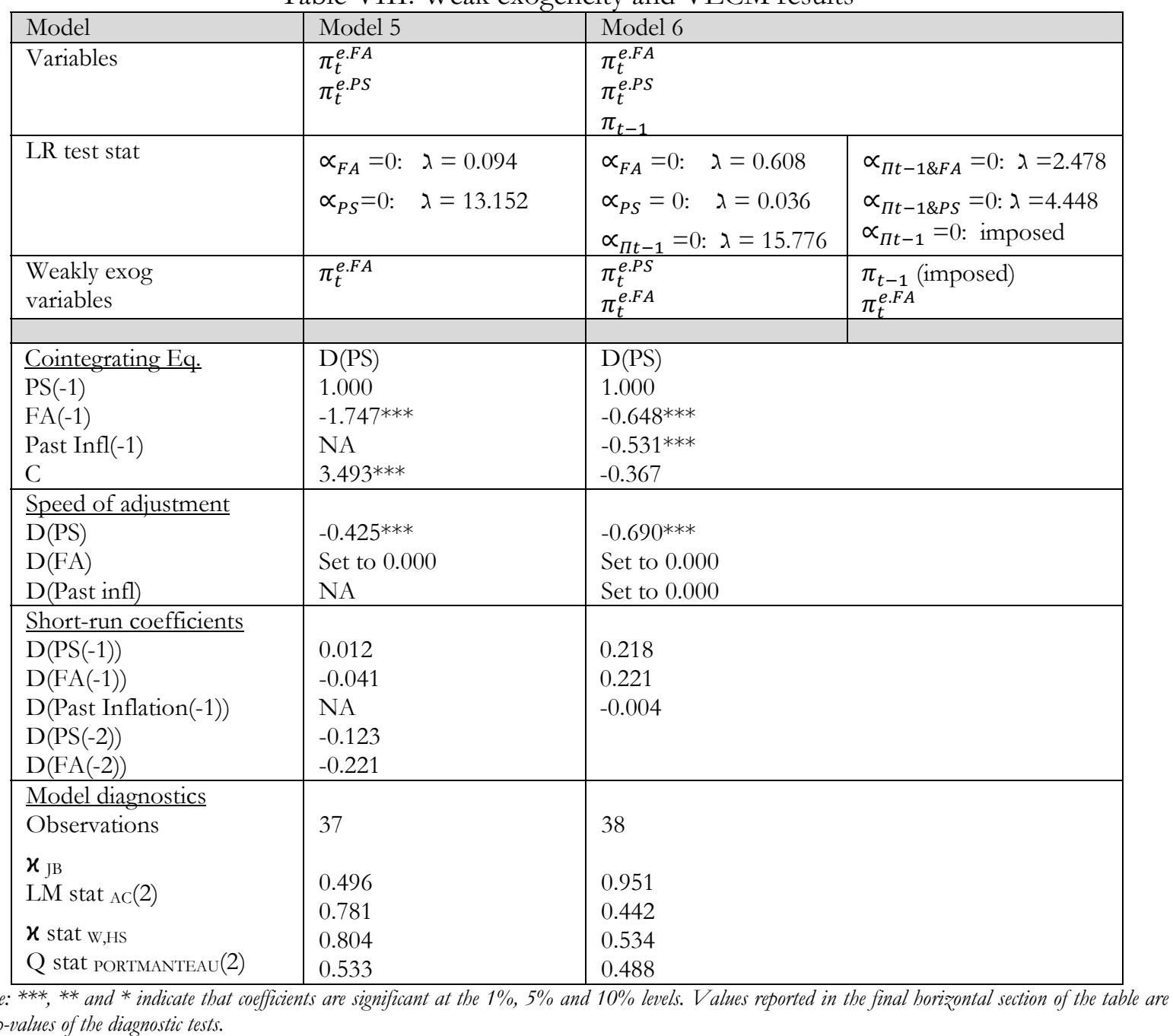

Therefore, past inflation was modelled as weakly exogenous and then the other two variables were again tested for weak exogeneity, conditional on the weak exogeneity of past inflation. In this case, $\pi_{\mathrm{t}}^{\mathrm{e} . \mathrm{FA}}$ is weakly exogenous and $\pi_{\mathrm{t}}^{\mathrm{e} . \mathrm{PS}}$ is identified as the dependent variable. The results for the VECM, estimated under this assumption, are reported in column 3 of Table VIII. The long-run coefficients on $\pi_{\mathrm{t}}^{\mathrm{e} \text {.FA }}$ and $\pi_{\mathrm{t}-1}$ reflect that both these variables play a sizeable and significant role in determining $\pi_{\mathrm{t}}^{\mathrm{e} . \mathrm{PS}}$ in the long run, and the estimated speed at which the inflation expectations of the prices setters was updated is 0.690 . 
Döpke et al. (2008) estimated information stickiness for France, Germany, the UK and Italy, and found that information stickiness for Italy was between 0.5 and 0.6 , while those of the other three countries ranged between 0.15 and 0.3. They argued that the level and uncertainty of inflation in Italy was much higher than in the other three and that it was therefore reasonable to expect inflation expectations to be less anchored. In order to explore this claim, OECD inflation data for the period studied by Döpke et al. (2008) was analysed (Table IX). The mean for inflation in Italy is indeed about 50\% higher than that of the other three countries in the study, although the standard deviation is not higher for the period. However, what are not observable from this data are the institutional features of the central banks in each of these countries and the level of credibility they have built over time. It is reasonable to suggest that in a country where the risks of inflation are greater, it is rational for the general public to pay more attention to developments in inflation and therefore to adjust their inflation expectations more rapidly. This reasoning is clearly in line with the higher estimate of information stickiness that was found for South Africa. The mean and standard deviation of inflation (for the sample period used to estimate South African information stickiness) are both clearly much higher than for the other four countries.

Table IX: Comparison of inflation characteristics in France, Germany, UK, Italy and South Africa

\begin{tabular}{|l|l|l|}
\hline & Mean & Standard Deviation \\
\hline France & 1.701 & 0.621 \\
\hline Germany & 2.094 & 1.420 \\
\hline UK & 1.990 & 1.235 \\
\hline Italy & 3.245 & 1.320 \\
\hline South Africa & 5.495 & 3.694 \\
\hline
\end{tabular}

Source: OECD (2011)

Note: The data sample periods for France, Germany, the UK and Italy is 1991Q4-2004Q4 (in line with the Döpke et al. (2008) study), whereas the data for South Africa is for the period 2000Q3-2010Q4. This was done in order to use the same data period as that used to estimate the information stickiness for each country.

Model 6 was then represented in the ARDL-ECM form, the results of which are reported in row 3 of Table X. The results of this ARDL model are close to that of the VECM, with the speed of adjustment coefficient 0.679 , compared with 0.690 from the VECM, and the long-run coefficient on 
past inflation was estimated to be only 0.044 higher. However the coefficient on $\pi_{\mathrm{t}}^{\mathrm{e} \text {.FA }}$ did drop by 0.125 , which changed the relative importance of $\pi_{\mathrm{t}}^{\mathrm{e} . \mathrm{FA}}$ and $\pi_{\mathrm{t}-1}$ in the long run $\pi_{\mathrm{t}}^{\text {e.PS }}$.

A range of diagnostic tests are reported for these ARDL models. The only result which raises any concern is that there is heteroskedasticity in model 6. This will not bias the coefficients, but will affect the standard errors. The model was re-estimated in two ways to confirm the results are still robust. Firstly, HAC standard errors were used and all the coefficients were still significant at the 1\% level. Secondly, an ARCH model ${ }^{8}$ was estimated, and the results were very close to those of the ARDL model, confirming that the results of ARDL model 6 are robust.

Modelling inflation expectations using a maximum of 40 survey-based observations is challenging. This was not a surprise and was identified in the introduction as the main reason that studies of this nature are limited. The VECM and ARDL models above offer reasonable estimates of South African information stickiness, supporting an estimate of between 0.65 and 0.70 . Finally, agentbased models are adopted in the following section to approach an estimation of sticky information from the opposite direction and to test the robustness of the results in another manner.

${ }^{8}$ The ARCH mode is only reported in Table XII in the appendix as the VECM and ARDL models are more appropriate for this study (as discussed in the text). 
Table X: ARDL models

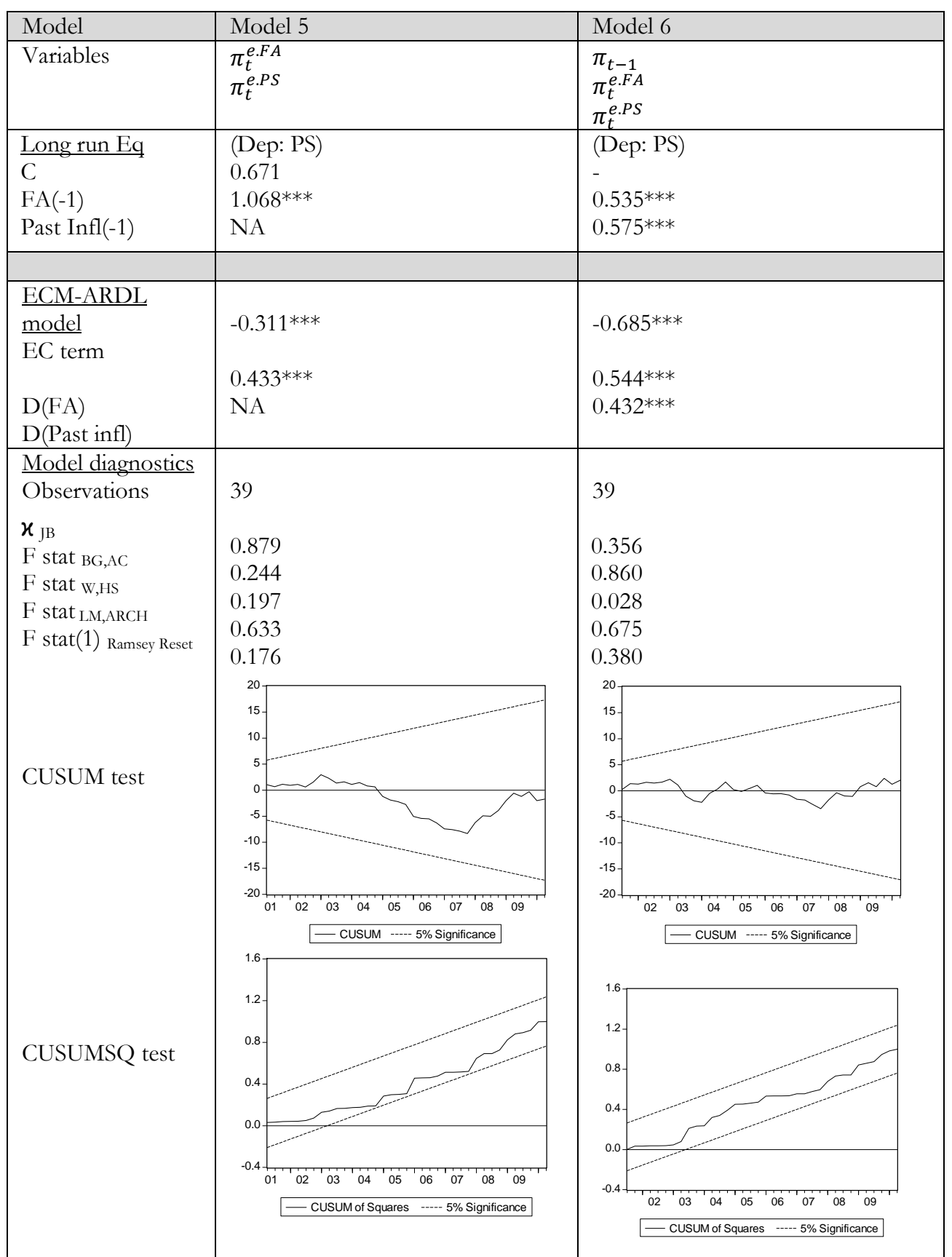

Note: The first horizontal section of the table indicates which variables are included in each model; the second reports the coefficients in the long-run equation of the ARDL model, and the third reports the results in the final ECM-ARDL model. ***, ** and * indicate that these coefficients are significant at the 1\%, $5 \%$ and $10 \%$ levels. Values reported in the final horizontal section of the table are the p-values of the diagnostic tests. 


\subsection{AGENT-BASED MODELS}

According to Tesfatsion (2006: 863), "The defining characteristic of ACE models is their constructive grounding in the interactions of agents, broadly defined to include economic, social, biological, and physical entities. ... Starting from an initially specified system state, the motion of the state through which time is determined by endogenously generated agent interactions." Crucially for this study, agent-based models begin at the disaggregated level. Given some real-world data, initial conditions for the inflation expectations of the price setters, and algorithms to describe their decision-making process, the interaction of the agents yields the simulated aggregate economic outcome. The aim of using an agent-based model in this paper was to assess whether the theory proposed to explain the formation of inflation expectations by the price setters is able produce a series similar to that observed in reality.

Matlab was used to simulate a $\pi_{t}^{\text {e.PS }}$ series (illustrated in Figure II). 10000 prices setters (i) were created. At time period $\mathrm{t}=1$, each price setter sets his inflation expectations based on the decision rule described in the theoretical model. Each price setter has a random probability $(\lambda)$ of updating his inflation expectations to those of the financial analysts (observed real-world data for the inflation expectations of financial analysts) and a probability of (1-ג) of retaining his own inflation expectations (the initial conditions set) ${ }^{9}$. If the price setter does not update his expectations to those of the financial analysts, he also has a random probability $\delta$ of adjusting his expectations in line with past inflation (observed real-world past inflation data), and a probability (1- $\delta$ ) of retaining his own inflation expectations from the previous period. When a price setter updates his inflation expectations based on past inflation, it is assumed that he read the past inflation figures in a newspaper and updated his expectations based on this information.

9 The inflation expectations of individual agents update separately, so the Matlab code keeps track of the inflation expectations of each price setter at each period. After the first time period, a decision by a price setter to retain his past inflation expectation means that a particular price setter retains the inflation expectation he had in the previous period. 
Once each price setter has made his decision in period 1, the average inflation expectation of the 10 000 price setters is calculated, and this becomes the first observation of the simulated $\pi_{t}^{e . P S}$ series. This is repeated for time periods $\mathrm{t}=1-40$ and results in a full simulated series of inflation expectations for the price setters in aggregate.

Figure II: The simulated model

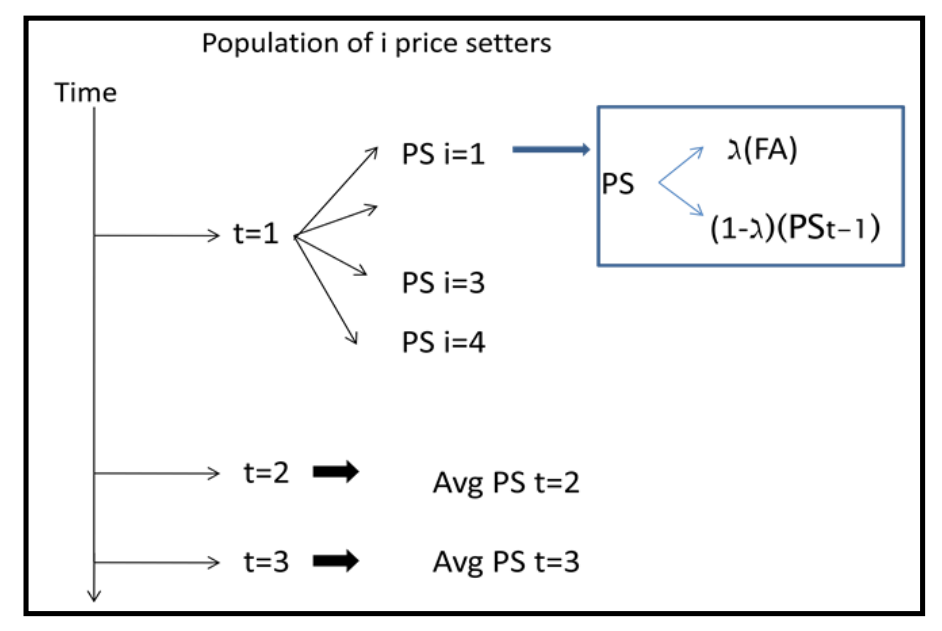

The simulated series can then be compared with the actual series to help judge the extent to which the theory can explain the actual inflation expectations of the price setters that are observed.

The results of the VECM and ARDL models used to estimate information stickiness in section 5, were used as a benchmark for setting the values of $\lambda$ and $\delta$ used in the decision-making algorithm of the price setters. Values of 0.37 for $\lambda$ and 0.70 for $\delta$ were selected as the starting points. The sensitivity of these two parameters were tested by varying the levels of each and then a range rather than a point was considered for each in order to test for heterogeneity. 
The results of this sensitivity analysis are reported in Table XIII. In each row, the values of $\lambda$ or $\delta$ are adjusted. Each row shows the results of the regression of a simulated series of $\pi_{\mathrm{t}}^{\mathrm{e} P \mathrm{PS}}$ on the actual observed $\pi_{t}^{e . P S}$ series. The values of $\lambda$ and $\delta$ set are reported in columns 2 and 3 . The estimated coefficient on the actual (true) $\pi_{\mathrm{t}}^{\text {e.PS }}$ in column 4 and the R-squared of the regression in column 5 are then used to judge the degree to which the simulated series matches the true series.

Table XIII: Agent-based model results

\begin{tabular}{|c|c|c|c|c|c|}
\hline Model & $\lambda$ & $\delta$ & $\begin{array}{l}\text { Coefficient } \\
\text { (Actual PS) }\end{array}$ & R-squared & $\begin{array}{c}\text { Test for } \\
\text { cointegration } \\
\end{array}$ \\
\hline & \multicolumn{2}{|c|}{ Testing lambda (level) } & & & \\
\hline 1 & 0.31 & 0.70 & 0.915 & 0.934 & Cointegrated \\
\hline 2 & 0.37 & 0.70 & 0.911 & 0.937 & Cointegrated \\
\hline \multirow[t]{2}{*}{3} & 0.43 & 0.70 & 0.907 & 0.934 & Cointegrated \\
\hline & \multicolumn{2}{|c|}{$\begin{array}{l}\text { Testing lambda } \\
\text { (heterogeneity) }\end{array}$} & & & \\
\hline 4 & $0.32-0.42$ & 0.70 & 0.911 & 0.937 & Cointegrated \\
\hline \multirow[t]{2}{*}{5} & $0.27-0.47$ & 0.70 & 0.911 & 0.937 & Cointegrated \\
\hline & \multicolumn{2}{|c|}{ Testing gamma (level) } & & & \\
\hline 6 & 0.37 & 0.60 & 0.906 & 0.937 & Cointegrated \\
\hline 7 & 0.37 & 0.65 & 0.909 & 0.938 & Cointegrated \\
\hline $2^{*}$ & 0.37 & 0.70 & 0.911 & 0.937 & Cointegrated \\
\hline \multirow[t]{2}{*}{8} & 0.37 & 0.75 & 0.913 & 0.936 & Cointegrated \\
\hline & \multicolumn{2}{|c|}{$\begin{array}{l}\text { Testing gamma } \\
\text { (heterogeneity) }\end{array}$} & & & \\
\hline 9 & 0.37 & $0.60-0.80$ & 0.911 & 0.937 & Cointegrated \\
\hline 10 & 0.37 & $0.50-0.90$ & 0.910 & 0.938 & Cointegrated \\
\hline
\end{tabular}

Note: Models 1-3 test the level of lambda and 4-5 the heterogeneity of lambda. Models 6-8 test the level of gamma, and 9-10 the heterogeneity of gamma. Note that model 2 is inserted

However, all the inflation expectations series are integrated of order 1, so there is a possibility that the regression results could be spurious. Therefore, the Engel-Granger test was used to establish whether the stimulated and actual inflation expectations series in each model are cointegrated. The results of this test for each of the models 1 to 10 are presented in column 6. Cointegration is found 
in all 10 models, confirming that the regression results are not spurious and allowing further comparison of the models.

Model 2 tested the fit of the simulated series when $\lambda$ was set at 0.37 and $\delta$ at $0.70^{10}$, and then the value of $\lambda$ was adjusted upwards and downward in models 1 and $3^{11}$. Both the coefficient and the Rsquared values are very high, suggesting that the simulated series is very close to the real series. The move upward to 0.43 delivered a poorer fit, but the adjustment downward to 0.31 gave an ambiguous result. In summary, it appears that a value for $\lambda$ of approximately 0.31 to 0.35 is reasonable. Models 4 and 5 consider the impact of assuming that price setters have a narrow and then a wider range of $\lambda \mathrm{s}$ (heterogeneity). Intuitively, this tests whether an assumption that the $\lambda \mathrm{s}$ of the price setters within a range offers a superior description of their inflation expectations. There was no sign of improvement by adding heterogeneity. Next, the level of $\delta$ set was adjusted upwards and downwards in models 6 to 8 . Notice that model 2, with the original benchmark values of $\lambda$ and $\delta$, is repeated in this section of the table to facilitate comparison. Lowering $\delta$ from 0.70 to 0.65 did not offer a clear improvement, but a further adjustment to 0.60 reduced the model fit. The adjustment of $\delta$ upward produced an ambiguous result. In summary, the value of $\delta$ appears to be approximately between 0.65 and 0.70 . Finally, models 9 and 10 tested the impact of assuming that price setters have a range of different values for $\delta$. Again, even when a high level of heterogeneity is assumed, the results were almost unchanged, so heterogeneous values of $\delta$ do not seem beneficial to model fit.

In conclusion, the best estimates from the model are that $\lambda$ is approximately 0.31 to 0.37 and $\delta$ approximately 0.65 to 0.7 . These ranges include the original values selected from the VECM and

\footnotetext{
$10 \lambda$ is set at 0.37 as this is midway between the two estimates of the speed of adjustment in model 5 , and $\delta$ is set at 0.70 as both speed of adjustment estimates for model 6 are close to 0.7 .

$11 \lambda$ is adjusted 0.06 upward and downward in order to consider both the VECM and ARDL speed of adjustment estimates for model 5 in section 5 .
} 
ARDL models and are not wide. Therefore, the agent-based models offer further support for the earlier estimates of information stickiness.

\section{CONCLUSION}

This paper explored the process by which South African price setters form inflation expectations. The aim is to understand this process better in order to communicate effectively with the general public as a group separate from financial analysts. Preliminary exploratory data analyses revealed that financial analysts adjust their inflation expectations quicker and more accurately than price setters. Then, survey data was applied to an epidemiological model (following the approach of Carroll (2002, 2003)) to model the dissemination of information about inflation through the South African economy and estimate information stickiness. Given the characteristics of the data and the nature of the research question, a combination of estimates of information stickiness from VECM and ARDL models were considered and an estimate of between 0.65 and 0.70 was accepted. Finally, agent-based models were adopted to approach the estimation of information stickiness from the disaggregated level upward and to test the robustness of the results. The agent-based models provided support for the earlier estimates. 


\section{APPENDIX}

Table VII: Results for single equation models for South Africa (based on Carroll $(2002,2003)$

\begin{tabular}{|c|c|c|c|c|c|c|c|c|}
\hline \multirow[t]{2}{*}{$\mathrm{Eq}$} & \multirow[t]{2}{*}{$\beta_{0}$} & \multirow[t]{2}{*}{$\beta_{1}$} & \multirow[t]{2}{*}{$\beta_{2}$} & \multirow[t]{2}{*}{$\beta_{3}$} & \multirow[t]{2}{*}{$\overline{R^{2}}$} & \multirow[t]{2}{*}{ DW } & \multirow{2}{*}{$\begin{array}{l}\text { Std } \\
\text { Err }\end{array}$} & Test \\
\hline & & & & & & & & p-value \\
\hline 1 & & $0.418^{* * *}$ & $0.649 * * *$ & & 0.919 & 1.727 & 0.450 & $\begin{array}{c}\beta_{1}+\beta_{2}=1 \\
0.000\end{array}$ \\
\hline 2 & -0.317 & $0.473 * * *$ & $0.368^{* * *}$ & $0.293 * * *$ & 0.949 & 1.935 & 0.374 & $\begin{array}{c}\beta_{1}+\beta_{2}=1 \\
0.248 \\
\beta_{1}+\beta_{2}+\beta_{3}=1 \\
0.030 \\
\beta_{3}=0 \\
0.004\end{array}$ \\
\hline 3 & & $0.444^{* * *}$ & $0.309^{* * *}$ & $0.336^{* * *}$ & 0.945 & 1.814 & 0.372 & \\
\hline
\end{tabular}

NOTE: The results in this table correspond to equation 2 in the text above. Columns 1-4 report the coefficient values for different versions of the equation and *** and ** indicate that these coefficients are significant at the 1\% and 5\% levels. Columns 5-7 report some diagnostics for each model, and column 8 reports the results of $W$ ald tests (with the relevant $p$-values in brackets). 
Table XI

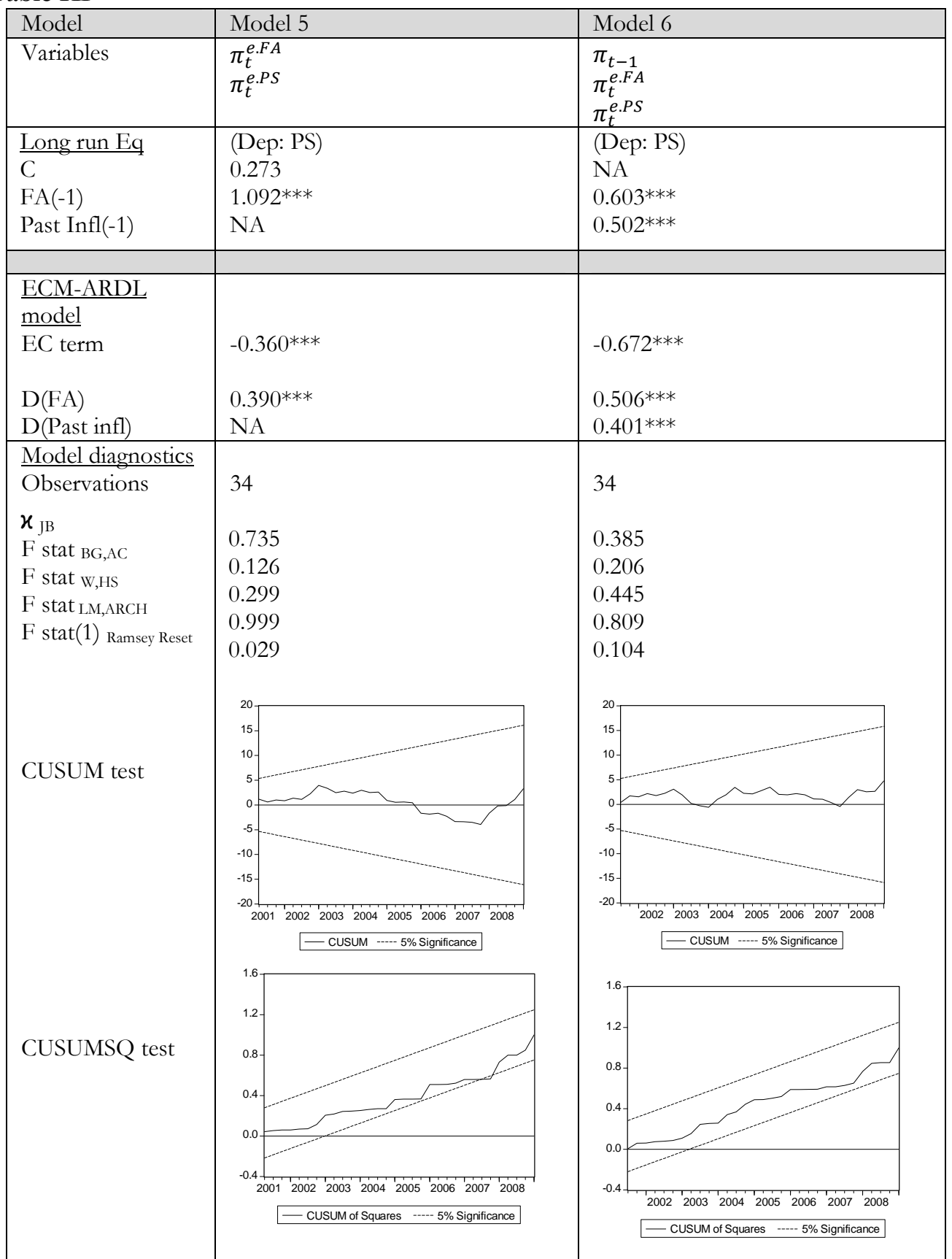

Note: The first horizontal section of the table indicates which variables are included in each model; the second reports the coefficients in the long-run equation of the ARDL model, and the third reports the results in the final ECM-ARDL model. ***, ** and *indicate that these coefficients are significant at the 1\%, $5 \%$ and $10 \%$ levels. Values reported in the final horizontal section of the table are the p-values of the diagnostic tests. 
Table XII

\begin{tabular}{|l|l|l|}
\hline & Variables & Coefficient Values \\
\hline Primary Equation & D(FA) & $0.507^{* * *}$ \\
& D(Past Infl) & $0.445^{* * *}$ \\
& EC Term $(-1)$ & $-0.695^{* * *}$ \\
\hline Variance Equation & C & 0.014 \\
& GARCH $(-1)$ & $0.909 * * *$ \\
\hline
\end{tabular}

Note: ***, ** and * indicate that these coefficients are significant at the 1\%, 5\% and $10 \%$ levels.

\section{REFERENCES}

BALL, L. (1991). The genesis of inflation and the costs of disinflation. Journal of Money, Credit and Banking 23, pp 439 452. BIRCHLER, U. and BÜTLER, M. (2007). Information Economics. New York: Routledge

BLINDER, A, EHRMANN, M, FRATZSCHER, M, DE HAAN, J and JANSEN, D. (2008). Central Bank Communication and Monetary Policy: A Survey of Theory and Evidence. European Central Bank, working paper no. 898, May 2008.

BUREAU FOR ECONOMIC RESEARCH. (2000-2009). Inflation expectations Surveys. www.ber.ac.za

BURNS, A. (1979). The Anguish of Central Banking. The 1979 Per Jacobsson Lecture.

CALVO, G. (1983). Staggered Prices in a Utility Maximizing Framework. Journal of Monetary Economics, 12 September: 383-398.

CARROLL, C. (2003). The Epidemiology of Macroeconomic Expectations. Paper written in connection with the conference "The Economy as an Evolving Complex System III' at the Santa Fe Institute in November 2001.

CARROLL, C. (2002). Macroeconomic Expectations of households and Professional Forecasters. Quarterly Journal of Economics, Volume 118, Number 1, February 2003.

CUKIERMAN, A. (2005). The Limits of Transparency. Presented at the session on "Monetary Policy Transparency and Effectiveness at the January 2006 Meeting of The American Economic Association.

DELLA VIGNA, S. (2007). Psychology and Economics: Evidence from the Field. National Bureau of Economic Research, working paper 13420

DöPKE, J. DOVERN, J. FRITSCHE, U and SLACALEK, J. (2008). Sticky Information Phillips Curves: European Experience. European Central Bank. Working Paper No. 930, September 2008.

DU PLESSIS, S and BURGER, R. (2006). A New Keynesian Phillips Curve for South Africa. Presented at the South African Reserve Bank Conference: Macroeconomic Policy Challenges for South Africa, 22-24 October 2006.

EHLERS, N and STEINBAUCH, R. (2010). The formation of inflation expectations in South Africa. South African Reserve Bank, working paper, WP/07/06.

EVANS, G and HONKAPOHJA, S. (2001). Learning and Expectations in Macroeconomics. Princeton University Press, Princeton.

FERGUSON, N and SCHULARICK, M. (2008). The "Thin Film of Gold": Monetary Rules and Policy Credibility in Developing Countries. National Bureau of Economic Research, working paper 13918.

FUHER, J. and MOORE, G. (1995). Inflation persistence. Quarterly Journal of Economics. Vol. 110(1), February , pp $127-$ 160.

FUHRER, J.C and MOORE, G.R. (1992). Monetary policy rules and the indicator properties of asset prices. Journal of Monetary Economics 29, pp $303-336$.

JUSELIUS, K. (2006). The Cointegrated VAR Model: Methodology and Applications. (Advanced Texts in Econometrics). Oxford: Oxford University Press.

KLAMER, A. (1984). New Classical Macroeconomics: Conversations with the New Classical Economists and their Opponents. Great Britain: Harvester Press.

LUCAS, R. (1972). Econometric Testing of the Natural Rate Hypothesis. In The Econometrics of Price Determination Conference. Otto Eckstein, ed. (Washington: Board of Governors of the Federal Reserve System).

MANKIW, G. (2001). The Inexorable and Mysterious Between Inflation and Unemployment. The Economic Journal, Royal Economic Society. Vol. 111(471), pp C45-61, May. 
MANKIW, G. and REIS, R. (2010). Imperfect Information and Aggregate Supply. Columbia University Department of Economics, Discussion Paper No. 0910-11.

MANKIW, G, and REIS, R, (2007). Sticky Information in General Equilibrium. Journal of the European Economic Association, April - May 2007.

MANKIW, G, and REIS, R. (2006). Pervasive Stickiness (Expanded Version). National Bureau of Economic Research, working paper no. 12024 .

MANKIW, G, and REIS, R. (2001a). Sticky Information Versus Sticky prices: A Proposal to Replace the New Keynesian Phillips Curve. National Bureau of Economic Research, working paper 8290.

MANKIW, G, and REIS, R. (2001b). Sticky Information: A model of Monetary Nonneutrality and Structural Slumps. National Bureau of Economic Research, working paper 8614.

MUSARD-GIES, M. (2005). Do ECB's statements steer short-term and long-term interest rates in the euro zone? The Manchester School, 74 (Supplement): 116-39.

NARAYAN, P. K. (2004). Reformulating Critical Values for the Bounds F-statistics Approach to Cointegration: An Application to the Tourism Demand Model for Fiji. Monash University Department of Economics Discussion Paper No. 02/04.

ORGANISATION FOR ECONOMIC COOPERATION AND DEVELOPMENT. (2011). OECD STATISTICS. http://stats.oecd.org/index.aspx. Accessed on: 27 May 2011.

ORGANISATION FOR ECONOMIC COOPERATION AND DEVELOPMENT. (2010). OECD Economic Surveys: South Africa 2010, OECD: Paris.

PESARAN, M.H., SHIN, Y. and SMITH,R. (1999). Bounds Testing Approaches to the Analysis of Long Run Relationships. Cambridge Working Papers in Economics 9907, Faculty of Economics, University of Cambridge.

PHELPS, E.S. (1978). Disinflation without recession: adaptive guideposts and monetary policy. Weltwirtschaftliches Archive 100, pp $239-265$.

PINDYCK, R.S. and RUBINFELD, D.L. (1998). Econometric Models and Economic Forecasts. Fourth Edition. Singapore: Irwin- McGraw.

REEVES, R and SAWICKI, M. (2007). Do Financial Markets React to Bank of England Communication? European journal of Political Economy, 23(1): 207-27.

REIS, R. (2004). Inattentive Consumers. National Bureau of Economic Research, working paper 10883.

ROBERTS, J. (1997). Is inflation Sticky? Journal of Monetary Economics, 173-196

ROBERTS, J. (1998). Inflation Expectations and the Transmission of Monetary Policy. Federal Reserve Board FEDS working paper Number 1998-43.

ROLNICK, A. (2007). An Interview with Chris Sims. Economist's View. http://economistsview.typepad.com/

SHEFFRIN, S.M. (1996). Rational Expectations. Cambridge University Press.

SIMON, H. A. (1955). A Behavioral Model of Rational Choice. The Quarterly Journal of Economics, Vol.69, No.1, pp 99 118.

SIMON, H. A. (1956). Rational choice and the structure of the environment. Psychological Review, vol. 63, March

SIMON, H. A. (1957). Models of Man, Social and Rational: Mathematical Essays on Rational Human Behavior in a Social Setting. New York: John Wiley and Sons.

SIMS, C. (2010). Rational Inattention and Monetary Economics. Handbook of Monetary Economics, 3B, edited by Friedman, $\mathrm{B}$ and Woodford, M. Amsterdam, North-Holland.

SIMS, C. (2005). Rational Inattention: A Research Agenda. Paper originally prepared for the Deutsche Bundesbank Spring Conference, May 2005.

SIMS, C. (1980). Macroeconomics and Reality. Econometrica 48:1-48.

SOLOW, R.M. (1956). A contribution to the theory of economic growth. The Quarterly Journal of Economics 70(1): 65-94.

STATISTICS SOUTH AFRICA. (2009a). The CPI new basket parallel survey: Results and comparisons with published CPI data. 3 Feb 2009.

STATISTICS SOUTH AFRICA. (2009b). The South African CPI Sources and Methods Manual. Release v.1. 3 Feb 2009.

TAYLOR, J.B. (1983). Union wage settlements during a disinflation. American Economic Review 73, pp 981 - 993.

TESFATSION, L. (2006). Handbook of Computational Economics, Volume 2: Agent-Based Computational Economics. Edited by Tesfatsion, L. and Judd, K.L. Amsterdam: North-Holland. 
